Matthias Vorgerd, Department of Neurology, Ruhr-University Bochum, Buerkle-de-laCamp-Platz 1, D-44789 Bochum, Germany).

COMMENT. Hereditary rippling muscle disease (RMD) is a rare autosomal dominant, nonprogressive myopathy characterized by increased muscle irritability (percussion-induced contractions), electrically silent wave-like contractions (rippling muscle), and muscle mounding with percussion. The above authors have previously reported mutations in CAV-3 in families with RMD and in one sporadic case of RMD. CAV-3 mutations may also occur in limb-girdle muscular dystrophy 1C, distal myopathy, and in children with elevated CK without myopathy.

\title{
LONG-TERM OUTCOME IN GUILLAIN-BARRE SYNDROME
}

The long-term sequelae and early predictors of sequelae were determined in a chart review of 47 children with Guillain-Barre syndrome (GBS) of whom 30 had been treated with intravenous gammaglobulin (IVIG) at The Hospital for Sick Children, Toronto, Canada. Persisting long-term muscle weakness at least 2 years after recovery was present in $23 \%$ of cases. Weakness was mild and patients were functionally independent. Risk factors for long-term muscle weakness were a young age at onset and a rapid progression to maximal weakness in the acute illness $(\mathrm{P}=0.03$ ). (Vajsar J, Fehlings $\mathrm{D}$, Stephens D. Long-term outcome in children with Guillain-Barre syndrome. J Pediatr March 2003;142:305-309). (Reprints: Jiri Vajsar MD MSc, Division of Neurology, The Hospital for Sick Children, 555 University Ave, Toronto, Ontario M5G 1X8, Canada).

COMMENT. Age associated changes in the symptomatology of GBS in children have been reported previously (Sakakihara Y, Kamoshita S. 1991, see Progress in Poediatric Neurology II, PNB Publ, 1994;pp271-2). Children between 3 and 9 years are most susceptible, and the total duration of the illness is longer in younger children. Bulbar nerves are most frequently affected in the younger age group, and the facial nerve in older patients. The stage of myelinogenic maturation might explain the age-associated changes in symptomatology of GBS.

\section{ATTENTION DEFICIT DISORDER}

\section{OROS METHYLPHENIDATE LONG-TERM STUDY IN ADHD}

Once-daily osmotic controlled-release (OROS) methylphenidate (Concerta) in the treatment of 407 children, aged 6-13 years, with ADHD who were known MPH responders, was evaluated in a 24-month multicenter, open-label, nonrandomized study, and reported from the Massachusetts General Hospital, Boston. In $289(71 \%)$ who completed 12 months'treatment, OROS MPH was well tolerated and effectiveness was maintained up to 12 months. Of 118 who failed to complete the trial period, $31(7.6 \%)$ discontinued for lack of effectiveness, and $28(6.9 \%)$ for adverse events, including tics (7), and insomnia (5). New onset of tics occurred in 23 (6.4\%) subjects. (Wilens T, Pelham W, Stein M, et al. J Am Acad Child Adolesc Psychiatry April 2003;42:424-433). 